\title{
A New Child Protection Strategy for Aboriginal Communities in Western Australia
}

\begin{abstract}
Despite numerous government inquiries and reforms, child sexual abuse in remote Aboriginal communities is a well-documented, ongoing problem. Established in Western Australia in 2009, Operation RESET is a multi-agency proactive community engagement initiative designed to improve the ability of communities and supporting agencies to detect, respond to and prevent child sexual abuse through the implementation of community engagement, capacity building and educational strategies. This comment describes the three core principles of Operation RESET: tackling child sexual abuse requires a collaborative, proactive approach between government and communities; the underlying causes and context of child sexual abuse must be recognised; and children's overall safety and wellbeing must be enhanced through integrated services that strengthen and empower families and communities. It also enumerates the seven phases of the operation's implementation, from identifying target communities to deploying an exit strategy. The comment ends by addressing the importance of empirical evaluation.
\end{abstract}

\section{Introduction}

It is well established that the prevalence of child sexual abuse in Aboriginal ${ }^{1}$ communities is significantly higher than that in the wider population (Stanley, Tomison and Pocock 2003). Although data related to the extent of sexual abuse (compared to other forms of abuse) is limited, child protection reports indicate that Aboriginal children are at least 7.7 times more likely than non-Aboriginal children to be the subject of substantiated incidents of harm (Australian Institute of Health and Welfare 2011). Further, the documented rate of child abuse in Aboriginal communities underestimates the true level of this crime, given that reporting of child abuse is much lower in Aboriginal than non-Aboriginal communities (Australian Institute of Health and Welfare 2009; Bromfield and Holzer 2008; Stanley, Tomison and Pocock 2003).

Numerous government inquiries have been implemented over the past few decades to address the high incidence and under-reporting of child sexual abuse in Aboriginal communities (eg, Anderson and Wild 2007; Crime and Misconduct Commission Queensland 2004; Gordon, Hallahan and Henry 2002; Mullighan 2008; New South Wales Aboriginal Child Sexual Assault Taskforce (NSWACSAT) 2006). Despite these inquiries and subsequent reforms, child sexual abuse has remained an ongoing concern, which highlights the complex and multifaceted nature of this problem (Calma 2006). Factors that contribute to the continued occurrence of child sexual abuse include inadequate understanding of the nature of this crime (and the laws that police it), and the existence of systemic structural barriers to individuals' engagement with welfare and law enforcement agencies due to shame, fear of payback and a lack of trust in criminal justice professionals (Lievore 2003; NSWACSAT 2006; Stanley, Tomison and Pocock et al 2003). Research also

The term Aboriginal will be used throughout the article to refer to Aboriginal peoples and Torres Strait Islanders. 
suggests that intergenerational cycles of poverty, poor health, violence, and drug and alcohol misuse are associated with heightened risk of family and other violence, including child abuse and neglect (Berlyn and Bromfield 2009). Family violence and child sexual abuse have become normalised and intergenerational in some remote Aboriginal communities. Narrowing the gap between Aboriginal and non-Aboriginal welfare outcomes requires deliberate, multifaceted, proactive community engagement strategies based on trust, capacity building and education (Stanley, Tomison and Pocock 2003).

One such multi-agency community engagement initiative established to tackle the high prevalence of child sexual abuse in remote Aboriginal communities is Operation RESET. The main factor that drove the development of Operation RESET was the low reporting by victims and low detection by authorities of sexual abuse in remote Western Australian (WA) communities that had a broad range of known risk factors associated with child abuse and family violence (eg, drug and pornography abuse, poor health and housing). Indeed, in several WA communities with numerous direct indicators of sexual abuse (eg, self harm, teenage pregnancies, sexually transmitted diseases (STDs) in children), this crime was almost non-existent in official statistics.

Operation RESET is a well-resourced joint initiative of the WA Police Sex Crime Division and the Department for Child Protection's ChildFIRST service, and has been active in numerous remote Aboriginal communities in the mid-west Gascoyne region of WA since April 2009. Operation RESET has since become the generic brand name for the intervention type across the regions. It is best described as a collaborative, proactive effort to build community understanding about the law, increase efficiency of public sector systems and build strong communities and cross-sector commitment to protecting children. The primary purpose of Operation RESET is to improve the ability of communities and supporting agencies to detect, respond to and prevent child sexual abuse through the implementation of an integrated model of victim management, community engagement, capacity building and educational strategies.

This comment seeks to outline the core principles underpinning the development of Operation RESET and the seven phases in its implementation. By providing an overview of the operation, this comment addresses the need for accountability, citizen-centric service design and transparency of government initiatives. The comment also addresses problems caused by a scarcity of literature outlining the intent, practical implementation and impact of prior and current reforms (Thompson, Greville and Param 2008). Most of the discussion about reforms has merely highlighted the failure of prior interventions and the need for more community engagement and a 'whole-of-government approach' to tackling the causes and symptoms of child sexual abuse in Aboriginal communities. This conceptual and practical analysis of Operation RESET, and, in due course, an evaluation of the operation's effectiveness, will assist in the future development of effective child protection and associated law enforcement strategies. 


\section{Core principles underpinning the development of Operation RESET}

The developers of Operation RESET ${ }^{2}$ believe that tackling child sexual abuse requires an integrated, proactive community engagement approach. Three core principles underpin this approach and are discussed below.

The first core principle underpinning Operation RESET is that tackling child sexual abuse requires a collaborative, proactive approach between community and government. An ideal collaborative partnership is one where there is genuine whole-of-community (not just victim) engagement and active participation of all stakeholders (ie, not merely consultation on the part of service providers). Collaborative inclusive partnership between government departments and communities serves three purposes. First, it utilises the expertise and resources of the community to ensure that interventions are culturally appropriate, maintained in the long term and well targeted to the needs of communities (Thompson, Greville and Param 2008). Second, genuine partnership is essential for the design and implementation of strategies that acknowledge the everyday realities that Aboriginal people live with and the multifaceted problems associated with child sexual abuse (Hunter 2008). Third, genuine partnership between government departments and communities facilitates the establishment and preservation of trust between Aboriginal community members and service providers. Trust is fundamental to the collaborative approach and is the central element underpinning disclosure of sexual crimes (Powell and Cauchi in press). This is particularly true in Aboriginal communities: trust in authorities has been greatly eroded by past adverse treatment, including colonisation and the forced removal of Aboriginal children from families and their placement in missions, with white families, and as apprentices or domestic servants between the 1860s and the early 1970s (Hunter 2008; Keel 2004; Mullighan 2008; Myhill 2006; NSWACSAT 2006). Since the 1960s, limited trust in service providers has been perpetuated by inadequate government responses and poor quality service delivery.

The need to recognise the underlying causes and contexts of child sexual abuse is the second core principle underpinning Operation RESET. Child sexual abuse in Aboriginal communities is a highly complex issue that relates to almost every other concern - health, housing, welfare, education and employment (Calma 2006). Thus, the framework for understanding child sexual abuse must move beyond an incident-focused, linear approach that examines individual actions towards children and isolated causes to an ecological or holistic approach that addresses the myriad of interconnected community, economic and individual factors associated with, and that impact upon, non-disclosure of abuse (Fawcett and Hanlon 2009; Gordon, Hallahan and Henry 2002). More specifically, intervention into child sexual abuse in Aboriginal communities needs to include programs that address the precipitating causes for abusive episodes (eg, health issues), the historical factors (eg, loss of cultural identity, cultural differences in childrearing practices, unresolved trauma and grief, breakdown of family and community structures), and situational factors (eg, substance abuse, unemployment and welfare dependency) (AIHW 2009; Hunter 2008; Memmott et al 2001; NSWACSAT 2006; Stanley, Tomison and Pocock 2003).

The third principle underpinning Operation RESET is that children's overall safety and wellbeing are enhanced through services that strengthen and empower families and communities (Bromfield and Holzer 2008; Fawcett and Hanlon 2009; NSWACSAT 2006;

The architects of the RESET model include Detective Inspector Sievwright and Detective Inspector Fairman of the WA Police, and Mr Glenn Mace, Director of ChildFIRST, Department for Child Protection. 
Scougall 2008). This principle is realised through Operation RESET's adoption of the capacity building process. Capacity building is an approach to community engagement and development that fosters independence (Garlick 1999). Specifically, it refers to the provision of assistance to groups or individuals in order to develop certain skills or areas of competence. Strategies for capacity building include professional development, training and other community engagement processes designed to address identified needs in targeted communities (United Nations Development Programme (UNDP) 1997; United Nations Economic and Social Council 2006). The RESET team considered the community engagement processes fostered by capacity building to be a prerequisite to improving outcomes for sexual abuse victims and delivering a whole-of-government response to the crime of child sexual abuse.

Together, the aforementioned three core principles form the foundation that supports the seven phases of Operation RESET's implementation. These seven phases are discussed below.

\section{Overview of Operation RESET's seven phases of implementation}

Operation RESET is designed to bring together different stakeholders to facilitate the identification of, and deliver tailor-made solutions for, child sexual abuse and related problems. While ultimately a joint initiative of WA Police's Sex Crimes Division and the Department for Child Protection's ChildFIRST service, this multi-agency strategy also requires the Department of Health and the Department of Education and Training to share responsibility in responding to child abuse by 'adding value' (ie, tapping into local knowledge through consultation, inclusion, problem solving and provision of resources), and by enabling regional services and communities to be creative and dynamic in preventing and responding to child abuse.

Operation RESET is a multi-layered, phased approach that acknowledges there is no 'one-size-fits-all' solution to dealing with child sexual abuse. Intervention strategies are tailored to particular communities' concerns and needs. The operation aims to ensure that victims and communities feel safe and supported following disclosure, throughout their contact with the criminal justice process and in the aftermath.

There were seven phases in Operation RESET's implementation in trial form in WA's mid-west Gascoyne region. The remainder of this section describes the seven phases and provides an explanation of their importance.

\section{Phase 1: Identification of target communities (risk assessment)}

Proactive interventions are costly initiatives; it was therefore not possible for government agencies to implement Operation RESET in all WA communities simultaneously. A decision needed to be made at the outset regarding which communities would be the focus of the initial trial. This decision was made by collating community demography and interagency intelligence for all Aboriginal communities across the state. Specifically, the risk of child abuse and neglect for individual communities $(\mathrm{N}=298)$ was identified using the 'Survey of Risk Factors for Child Abuse in Regional/Remote Communities'. ${ }^{3}$ The survey elicits information from agencies about the extent to which several factors that contribute to an increased risk of child abuse and neglect (eg, pornography, violence) are present in

\footnotetext{
3 A survey developed by WA Police and the Department for Child Protection: $<$ http://www.simpledatamanagementsystems.com.au/dcp/93h92_dcp_index.html $>$.
} 
Aboriginal communities. Scores for each risk factor are combined to provide an overall risk rating (out of 100) for child abuse in each community. The risk scores are subsequently recorded on the vertical axis of an assessment matrix with sexual assault reports (on a per capita basis) recorded on the horizontal axis. Evaluation of the survey statistics revealed an extremely low rate of reporting and detection of child abuse within several high-risk communities. Those communities were subsequently chosen as the initial targets of Operation RESET.

\section{Phase 2: Compiling the core project team}

The second task in the implementation of Operation RESET involved the establishment of a core team (hereby referred to as 'the RESET team'). The RESET team consisted of seven professionals, including a senior investigation officer (SIO) detective sergeant, ${ }^{4}$ specialist child abuse detective investigators from the Sex Crime Division's Child Abuse Squad, and prescribed Specialist Forensic Child Interviewers attached to the Department for Child Protection ChildFIRST service and the Police Child Assessment Interview Team. The function of the RESET team was to address under-reporting of child sexual abuse by the following methods: (a) acting in a coordination role through network and stakeholder management; (b) assisting in the delivery of a proactive, targeted response; (c) having a visible presence in communities; and (d) working with existing service providers to strengthen relationships, build capacity, problem solve and engage with the community to build trust and rapport.

Members of the RESET team were selected on the basis of specialist knowledge in child sexual abuse investigation (including child investigative interviewing, victimology, sexual abuse and the interrelationship between causal factors), as well as personal attributes (eg, good listening skills, positive track record of working with remote communities). Importantly, the RESET team included Aboriginal Specialist Child Interviewers who were able to speak the local languages and were aware of local history, culture and traditions in the communities where RESET was being implemented.

There were three reasons for compiling a RESET team rather than relying on existing local community service providers to implement the project. First, the creation of a purpose-built team ensured that the best experts and role models would be overseeing the program. There was greater assurance of establishing trust and rapport with an independent team because there was no history of interaction with individual RESET team members to taint community members' perceptions of the program.

Second, it was deemed important that the RESET team would work alongside the community, but that they would not be a permanent fixture in the community. Being mobile, the RESET team could provide a constant visible presence during community visits. This was considered necessary for demonstrating genuine commitment and partnership, promoting and spreading awareness of the new system, and gathering information from community members and passing on information about what they do.

Third, the heavy workloads of and demands on existing local service providers were considered relevant to the creation of an independent team. An independent RESET team could devote themselves full-time to the program and community engagement because they were not tied to the constraints of case management and general duties.

In this role, SIO Detective Sergeant Burnett from WA Police was accountable for the tactical implementation of the model and its outcomes. 


\section{Phase 3: Consultation with community members and service providers}

The RESET developers held a series of formal and informal briefings, consultations and inter-agency meetings with representatives from all local service provider groups, as well as with a broad range of community members. The main purpose of these briefing sessions was to provide information (including intelligence data) to assist the stakeholders to understand the dynamics of under-reporting and the full nature and prevalence of child sexual abuse in their region, catchment area or community. During these meetings, professional knowledge (eg, statistics) was articulated by RESET team members, who also drew on the knowledge and wisdom of the community through questions and discussion. In this sense, the approach of the RESET team during these meetings was similar to the 'Signs of Safety' solution-focused approach of Turnell and colleagues (Turnell 2008; Turnell and Edwards 1999).

The key local stakeholders involved in the implementation of Operation RESET included WA Police, the Department for Child Protection, the Department of Education and Training, the Department of Health, the Department of Corrective Services, Youth Justice, Justice Department, Geraldton Regional Aboriginal Medical Service (GRAMS), Chrysalis Services (crisis accommodation and support for victims of abuse), Department for the Attorney General (Victim Support Services and the Child Witness Services), Foodbank WA, local shires, the Department of Indigenous Affairs, family support services, a broad range of community groups, and community leaders.

During this consultative and assessment phase of the operation, it became clear to community members from across the region in which RESET was operating that there were indicators and anecdotal evidence of much higher levels of child sexual abuse than the official reporting statistics were demonstrating. Initial discussions with stakeholders showed the RESET team that results from RESET's operation could not be limited to measuring apprehension of offenders or substantiation of offences, or even the reporting of offences. Although these are important indicators of program success, the outcome of RESET also had to be measured in terms of improvement in community safety and understanding of the signs and indicators of abuse and victimology (by professionals and community), improvement in general conditions in communities, the strengthening of relationships between communities and government agencies, and the provision of consistent and timely support for child abuse victims (as reflected in greater community satisfaction and more community trust to approach agencies with concerns).

Communication between the RESET team, community members and local service providers was an ongoing process, not just during the initial development stage. Information flowed from the strategic level down to the operational level and vice versa, as well as between members of communities on the ground level (via informal interactions).

\section{Phase 4: Devising and implementing the community engagement strategy and safety plan (action phase)}

The action phase of Operation RESET refers to the management and implementation of cross-government initiatives during periods of deployment (ie, when the RESET team visited communities). The visits were highly structured and planned well in advance to ensure that adequate notice and consultation were given to each of the service providers involved in the targeted communities and to ensure that the team worked to its full capacity and employed activities appropriate to tasks. There were occasions when visits were unannounced, but this was usually to coincide with arrests being made. 
Deployment activities implemented by the RESET team fell into two categories: proactive (pre-planned 5-day period per month) and reactive (2- to 5-day period on demand). Teams required for the proactive deployment included five to six investigators and two Specialist Child Interviewers. A typical example of the workload for the proactive deployment was the completion of between 8 and 19 investigations as well as general rapport/networking and capacity-building tasks. During a reactive deployment, team numbers were assigned according to the priority and resources required. A typical reactive deployment consisted of two investigators and two Specialist Child Interviewers from Police and the Department for Child Protection. Prior to each reactive and proactive deployment a team briefing occurred where individual RESET officers and Specialist Child Interviewers were allocated tasks, and members began preparing for criminal investigations and interactive community events.

Overall, during 2009-2010, the RESET team conducted over 350 meetings with stakeholders within the mid-west Gascoyne, as well as awareness sessions, information sharing, problem solving and capacity building. Operations included the following: raising awareness of child abuse by regular sharing of data and intelligence; providing training to school staff and families in protective behaviours and indicators of abuse; increasing support to victims after arrests; connecting victims and families with local support services; building rapport between service providers and children in the classroom and sporting fields; and establishing food programs to enhance the overall wellbeing of children.

\section{Phase 5: Documentation of activities and outcomes}

Throughout the implementation of Operation RESET, activities and case outcomes were recorded on a 12-month Gantt chart (for more information on Gantt charts, see $<\mathrm{http}$ ://archive.org/details/ganttchartworkin00claruoft $>$ ). The purpose of this was to provide a visual representation of the duration and frequency of tasks against the progression of time. This documentation provided a framework for planning and scheduling community interactions, for giving feedback to stakeholders, and for future evaluation (ie, to enable identification of the combination of strategies that were activated at the time disclosures were made); it was also an intelligence tool for informing the strategic direction of the project. Documentation of strategies enabled the RESET team to quickly assess the frequency of activities and contact with service providers, which is critical for ensuring equitable distribution of services across the region and throughout the period of the operation.

\section{Phase 6: Review of initiatives}

The establishment of any valid and reliable process requires ongoing quality control evaluation. Quality control evaluation refers to a system of maintaining standards of service delivery by testing samples of output against certain success indicators. For any organisation to effectively fulfil its service obligations, quality control evaluation and iterations need to be regular, built-in components of the system.

Since its inception, evaluation of Operation RESET has consisted of two parts. First, evaluation is implemented on a day-to-day (ground) level, through the exchange of information among community members and front-line workers and through investigations and assessment of new intelligence. Ongoing anecdotal feedback allowed the trial RESET team to prioritise activities and organise schedules, and it ensured communities were active participants in the intervention. To illustrate, the RESET team received feedback from one community concerning the community's lack of knowledge about the age of consent for sex; this meant people were breaking the law without realising it. The RESET team were able to 
work with local women's groups to produce an 'educational talking poster', a powerful tool that informed the community about law and consent - a tool that was created, developed and owned by those women's groups.

Operation RESET's second type of evaluation is more formal. It consists of several parts: an attitude survey of 16 questions asking community members to scale between 0 and 10 whether they agree or disagree with a particular statement (eg, Has your community increased its knowledge around child sex abuse?); and a qualitative evaluation of in-depth interviews with stakeholders and community members about RESET's impact. Those participating in the in-depth interviews after the trial intervention were given 10 broad, open-ended prompts and invited to say what they liked about the operation. While the evaluation of Operation RESET will be the subject of future articles, to date feedback from interviewees has been overwhelmingly positive, and this positive response has been reinforced through a third vital element of the operation's evaluation: hard outcome indicators. Data from communities in the trial region (eg, reporting and arrest rates) was collated in relation to all aspects of the operation on a routine basis so that the procedures and their impacts could be clearly understood by all parties. One significant finding was that in the 18 months of RESET's trial period there was an 80 per cent increase in reporting. Notifications to other organisations such as Department for Child Protection also increased. The reports were not made in a random fashion; there was a strong correlation between reporting and the team being present in communities, which can be viewed as evidence for how rapport-building changes people's behaviour.

\section{Phase 7: Deployment exit strategy}

Operation RESET can only be implemented in each community on a temporary basis (ie, 12-18 months) because of the immense financial cost involved in running the program and the large number of Aboriginal communities in WA. When the initial 18-month trial was coming to an end, the concern was to maintain the good work of the specialist dedicated RESET team in locally driven versions of the operation. The trial of Operation RESET was unique for many reasons, one of which was its untested nature. Because of this, local agencies had adopted a 'wait-and-see' approach to RESET, and it was only when the operation had clearly been a success that WA Police, Department for Child Protection and others were ready to discuss long-term local staffing commitments to the model when the RESET team exited. As a consequence, the exit strategy from the trial intervention involved introducing a new set of faces to the communities in the trial region; but to maintain the public perception of continuity, as well as continuity in the program, the new team were called District RESET. New staff members were provided with in-depth training on the model's theoretical, legal and practical requirements to enable them to fulfil their specialist role. The RESET team ran week-long deployments into the trial region's communities to introduce District RESET members. District RESET has now been running for a year, and each quarter the team receives a visit from key RESET personnel to gauge the success of the local version of the operation.

Since the success of the Operation RESET trial, more recent deployments of the RESET team have exited from their regions differently. Operation RESET in the Pilbara region included local and permanent Department for Child Protection workers, who have been learning from and working with the RESET team, and will be in a better position to implement RESET strategies. During the RESET team's next operation in the Kimberley region, local agencies will be actively involved from the outset. 
Exiting the RESET team will always be a challenge, and evaluation of this stage must be longitudinal. Reporting rates are likely to stagnate (at least initially) as community members adjust to the change, develop relationships with the new team and assess whether the new team is able and willing to maintain the level of service offered under RESET. However, as local workers become more involved in the RESET team at the beginning of each operation, the transition from team to District RESET will become less of a hurdle for RESET workers and community members.

\section{Conclusion}

Operation RESET is a very different type of service delivery to what has previously been offered throughout Australia. Its distinctive features include the following: the establishment of genuine consultation between the operation team, local stakeholders and community members; proactive service delivery through capacity building; and an emphasis on self-determination among community members and service providers. The model was not created to provide the answers or solutions to the many specific and associated problems of child abuse and family violence in remote communities. Rather, it provides a tangible process through which the different stakeholders can come together to identify strengths and problems, design collective solutions and craft a unified plan for the region or community. The intentions underlying Operation RESET are that Aboriginal communities themselves (with support of service providers) effectively prevent the sexual abuse of their children and that complaints made to the police and child protection service providers are investigated thoroughly and expeditiously.

The current comment is purely descriptive in nature. The aim was to articulate the RESET process, its rationale and how it was initially implemented in remote Aboriginal communities in the mid-west Gascoyne region of WA. The next step will be an empirical evaluation of this program. While Operation RESET has had considerable support from communities and was the recipient of the 2010 WA Premier's Award for Excellence in Public Sector (category: Improving Government), the true test of its effectiveness will be through in-depth analysis of stakeholders' perceptions and the evaluation of hard outcomes such as reporting rates of abuse and other indicators of community wellbeing.

\section{Glenn Mace}

Director, ChildFIRST, Department for Child Protection, Western Australia; Co-developer, Operation RESET

\section{Martine Powell}

Professor, School of Psychology, Faculty of Health, Deakin University 


\section{Acknowledgements}

In relation to the scoping and delivery of Operation RESET, the authors acknowledge the support of WA Police Sex Crime Division Detective Superintendent Graeme Castlehow, Detective Inspector Bob Kirby, Mid-West Gascoyne Police District Superintendent Ross Tomasini, Department for Child Protection Executive Director Cheryl Barnett, members of the communities, local service providers and the RESET team. Thanks also to Mairi Benson and Rebecca Steinberg who assisted with the collation of literature and manuscript editing.

\section{References}

Anderson P and Wild R (2007) Ampe akelyernemane meke mekarle: Little children are sacred. Report of the Northern Territory Board of Inquiry into the protection of Aboriginal children from sexual abuse, Northern Territory Government, Darwin

Australian Institute of Health and Welfare (AIHW) (2009) Child protection Australia 2007-08, AIHW, Canberra

Australian Institute of Health and Welfare (AIHW) (2011) Child protection Australia 2009-10, AIHW, Canberra

Berlyn C and Bromfield L (2009) Child protection and Aboriginal and Torres Strait Islander children, Australian Institute of Family Studies, Melbourne

Bromfield L and Holzer P (2008) A national approach for child protection: Project report, National Child Protection Clearinghouse, Australian Institute of Family Studies, Melbourne

Calma T (2006) Ending family violence and abuse in Aboriginal and Torres Strait Islander communities - Key issues: An overview paper of research and findings by the Human Rights and Equal Opportunity Commission 2001-2006, Human Rights and Equal Opportunity Commission, Canberra

Crime and Misconduct Commission Queensland (CMC) (2004) Protecting children: An inquiry into abuse of children in foster care, CMC, Brisbane

Fawcett B and Hanlon M (2009) 'Child sexual abuse and Aboriginal communities in Australia: A case study of non-inclusive government intervention', European Journal of Social Work 12(1), 87-100

Garlick S (1999) Capacity building in regional Western Australia: A regional development policy for Western Australia, Department of Trade and Commerce, Government of Western Australia, Perth

Gordon S, Hallahan K and Henry D (2002) Putting the picture together: Inquiry into response by government agencies to complaints of family violence and child abuse in Aboriginal communities, Department of the Premier and Cabinet, Government of Western Australia, Perth

Hunter SV (2008) 'Child maltreatment in remote Aboriginal communities and the Northern Territory Emergency Response: A complex issue', Australian Social Work 61(4), 372-88 
Keel M (2004) Family violence and sexual assault in Indigenous communities walking the talk, ACSSA Briefing No 4, Australian Centre for the Study of Sexual Assault (ACSSA), Australian Institute of Family Studies, Melbourne

Lievore D (2003) Non-reporting and hidden recording of sexual assault: An international literature review, Commonwealth Office of the Status of Women, Canberra

Memmott P, Stacy R, Chambers C and Keys C (2001) Violence in Indigenous communities, Commonwealth of Australia, Canberra

Mullighan EP (2008) Children in state care and children on APY lands: Commission of Inquiry, Government of South Australia, Adelaide

Myhill A (2006) Community engagement in policing: Lessons learnt from the literature, Home Office, London

New South Wales Aboriginal Child Sexual Assault Taskforce (NSWACSAT) (2006) Breaking the silence: Creating the future. Addressing child sexual assault in Aboriginal communities in New South Wales, New South Wales Government, Sydney

Powell MB and Cauchi R (in press) 'Victims' perceptions of a new model of sexual assault investigation adopted by Victoria Police', Police Practice and Research

Scougall J (2008) Lessons learnt about strengthening Indigenous families and communities: Stronger Families and Communities Strategy 2000-2004, Occasional Paper No 19, Department of Families, Housing, Community Services and Indigenous Affairs, Australian Government, Canberra

Stanley J, Tomison AM and Pocock J (2003) Child abuse and neglect in Indigenous Australian communities, National Protection Clearinghouse Issues Paper No 19, Australian Institute of Family Studies, Melbourne

Thompson SC, Greville HS and Param R (2008) 'Beyond policy and planning to practice: Getting sexual health on the agenda in Aboriginal communities in Western Australia', Australia and New Zealand Health Policy 5(3), <http://www.anzhealthpolicy.com/ content $/ 5 / 1 / 3>$

Turnell A (2008) Adoption of the Signs of Safety as the Department for Child Protection's child protection practice framework: background paper, Department for Child Protection, Government of Western Australia, Perth

Turnell A and Edwards S (1999) Signs of safety: A safety and solution oriented approach to child protection casework, WW Norton, New York

United Nations Development Programme (UNDP) (1997) Governance for sustainable human development, UNDP policy document, United Nations, New York

United Nations Economic and Social Council (2006) 'Definition of basic concepts and terminologies in governance and public administration', Compendium of basic terminology in governance and public administration, Committee of Experts on Public Administration, $5^{\text {th }}$ session, Agenda Item 5, E/C.16/2006/4 